\title{
Vulnerable and without protection: Lifetime experiences of abuse and its influence on mental ill health
}

\author{
—An interview study among Swedish women within general psychiatric care
}

\author{
Karin Örmon $^{1,2,3^{*}}$, Marie Torstensson-Levander ${ }^{4}$, Charlotta Sunnqvist ${ }^{1,2,3}$, Christel Bahtsevani ${ }^{1,3}$ \\ ${ }^{1}$ Department of Care Science, Faculty of Health and Society, Malmö University, Malmö, Sweden \\ ${ }^{2}$ Advance Nurse in Psychiatric and Mental Health care (APNs), Faculty of Health and Society, Malmö University, Malmö, Sweden \\ ${ }^{3}$ Registered Nurse (RN), Malmö University, Faculty of Health and Society, Malmö, Sweden \\ ${ }^{4}$ Department of Criminology, Faculty of Health and Society, Malmö University, Malmö, Sweden \\ Email: *karin.ormon@mah.se
}

Received 28 November 2013; revised 28 December 2013; accepted 8 January 2014

Copyright (c) 2014 Karin Örmon et al. This is an open access article distributed under the Creative Commons Attribution License, which permits unrestricted use, distribution, and reproduction in any medium, provided the original work is properly cited. In accordance of the Creative Commons Attribution License all Copyrights (c) 2014 are reserved for SCIRP and the owner of the intellectual property Karin Örmon et al. All Copyright (C) 2014 are guarded by law and by SCIRP as a guardian.

\section{ABSTRACT}

Violence against women is a major global public health issue, and experiencing violence has substantial consequences for the lives of abused women. This study aims to illustrate experiences of abuse and its influence on mental ill health among women seeking general psychiatric care. Ten women seeking general psychiatric care in southern Sweden participated in a qualitative interview study. Content analysis resulted in four categories: Living in fear that persistently influences the substance of life, living with the sense of being worthless, living with a constant question about who you are and living between hope and despair. The theme evolving from the analysis was: Being vulnerable and without protection in a frightful reality that limits one's possibilities of living and being the person one wishes to be. The results showed that the women described their mental ill health not only in terms of depression, anxiety and suicidal ideation and self-harm, but also in relation to feelings of hope and despair, fear, worthlessness and living with a constant question about who they are. The abuse reduces freedom of action, and leads to feelings of insecurity, of not having any boundaries, isolation, and self-contempt and a need to escape. This study provides knowledge of abused women self-reported mental ill health in relation to abuse.

\section{KEYWORDS}

Content Analysis; General Psychiatric Care; Mental

${ }^{*}$ Corresponding author.

\section{Ill Health; Violence against Women}

\section{INTRODUCTION}

Being abused by a husband or intimate male partner is one of the most common types of violence committed against women [1]. A population study, concerning ending violence against women, reported that at least one of three women has been subjected to abuse during their lifetime [2]. The perpetrator is the most common member of the abused woman's family [2]. That makes violence against women a major global public health issue which is supported by international research e.g. [3-5]. According to the World Health Organization [6], 20\% of women had been sexually abused as children and $25 \%$ $50 \%$ of all children had been abused physically. Research also indicates that maltreated children have an increased risk of mental disorders throughout their life course [7].

In this study we term the violence committed to the women as interpersonal violence, which, according to Krug et al. [4], entails physical, sexual, psychological abuse and deprivation or neglect. These phenomena are divided into family and partner violence and community violence [4]. Other terms found in research on violence against women include domestic violence, battered women and intimate partner violence [8]. The term genderbased violence evolves from women's subordinate status [2]. The use of diverse terminology is one of the obstacles facing researchers on violence against women [9, 10].

Another well-known fact is the association between ex- 
perience of violence and mental ill health [11-15]. Mental ill health is an overarching definition including mental disorders and milder psychological problems or distresses which generate personal suffering but not necessarily a psychiatric diagnosis [16].

Experiencing domestic violence is associated with high rates of health care admission, and use of prescribed medication as well as impact on health [13]. A review by Dillon et al. reported women's experiences of interpersonal violence and an association with mental health problems such as depression, PTSD, anxiety, self-harm, and sleep disorders [15]. Another review reported a high prevalence of domestic violence in psychiatric populations where female psychiatric inpatients, lifetime prevalence ranged from $34 \%$ to $63 \%$ [17]. That is supported by a systematic review of 134 international studies by Alhabib et al. [18] measuring prevalence of domestic violence. Those results showed the highest prevalence's in psychiatric and obstetrics/gynecology settings compared to research setting such as population based, primary/community health and hospital [18]. A Swedish study investigating physical, sexual, emotional, and economic abuse using a self-administered questionnaire found a high prevalence of abuse in female users of psychiatric services. The women in the study who used psychiatric services $(n=1382)$ reported a $53 \%$ prevalence of childhood abuse and a $63 \%$ prevalence of abuse during adulthood [19]. A review by Oram et al. [20] which aimed to estimate prevalence of different types of domestic violence reported a median prevalence of partner violence of 33\% among women in psychiatric out-patient care. The prevalence among female in-patients was 30\% [20].

The Swedish Society of Nursing and the Swedish Association of Psychiatric and Mental Health Nurses [21] have a clear policy. Psychiatric and mental health nurses should promote patient's ability to recover from mental ill health, identify and prevent health risks and reduce suffering [21]. Carretta [22] describes how nurses should actively develop health care planning and address the subject of violence against women. This health concern could be directly addressed through screening, support and assistance. Coker et al. [12] also highlights the importance of identifying intimate partner violence in order to reduce the consequences and make it a health priority. To be able to do so, nurses have to be aware of the selfreported experiences of mental ill health as described by abused women. Research has highlighted difficulties for nurses addressing the abuse. Almost half of the nurses working in primary health care reported that they never or only sometimes asked questions concerning intimate partner violence [23]. Difficulties of asking were due to not knowing how to ask and not knowing what to do with the answer. Concerns about woman's integrity, lack of time and a feeling of being uncomfortable were also reported [23]. Questions about experience of violence were mostly asked whether the woman had physical injuries. Only 48 per cent of the nurses considered mental/psychosomatic problems to be an indication of intimate partner violenssce.

It could be difficult for clinicians and nurses to discern which symptoms are due to mental health status and which are symptoms of abuse. This study contributes to the knowledge of abused women's experiences described in their own words and will hopefully enrich the knowledge of abused women within general psychiatric care.

This study aims to illustrate experiences of physical, emotional and/or sexual abuse and its influence on selfreported mental ill health among women seeking general psychiatric care.

\section{MATERIALS AND METHODS}

A qualitative approach was used to explore the phenomena of experiencing abuse and mental ill health among a group of women attending general psychiatric care. The use of an inductive approach provides an opportunity to gain greater knowledge of the women's own description and lived experience of abuse and their perceptions of its impact on their mental ill health. The inductive approach allows the researcher to penetrate the text in order to identify themes and phenomena of importance [24].

\subsection{Setting and Procedure}

Women attending a general psychiatric clinic in a southern urban area in Sweden, during September and October 2010 and September and October 2011, were requested to participate in a previous research study by answering a questionnaire. The study aimed at describing mental ill health in abused women and their experiences of physical, emotional, and sexual abuse. A form for consent to receive written information concerning participation in future studies was provided together with the questionnaire. Sixteen women volunteered to be interviewed in the present study after receiving the written information, but six later declined or were absent. Oral information was given and a time and place for the face-to-face interview was planned. In this present study, to be included all of the women should have endured violence as a child, adult or both. The women had also in the previous questionnaire indicated a connection between experiences of abuse and seeking care at the general psychiatric clinic. Ten women participated in the study. One of the participants was recruited through information at the clinic. All of the informants chose to be interviewed at the University where all the interviews were conducted by the first author.

\subsection{Participants}

The 10 participating women (see Table 1 ) had all sought 
Table 1. Demographics regarding participating women $(n=10)$.

\begin{tabular}{|c|c|}
\hline Age & \\
\hline $20-30$ & 4 \\
\hline $31-40$ & 4 \\
\hline 41- & 2 \\
\hline \multicolumn{2}{|l|}{ Country of birth } \\
\hline Sweden & 8 \\
\hline Other & 2 \\
\hline \multicolumn{2}{|l|}{ Years of education } \\
\hline 9 years or less & 1 \\
\hline 10 - 12 years & 6 \\
\hline 13 years or more & 3 \\
\hline \multicolumn{2}{|l|}{ Marital status } \\
\hline Single & 4 \\
\hline Partner & 6 \\
\hline \multicolumn{2}{|l|}{ Income source } \\
\hline Employed & 4 \\
\hline Unemployed or employment training courses & 2 \\
\hline Sick leave & 3 \\
\hline Student & 1 \\
\hline \multicolumn{2}{|l|}{ Experience of abuse } \\
\hline Emotional & $9 / 10$ \\
\hline Physical & $7 / 10$ \\
\hline Sexual & $7 / 10$ \\
\hline \multicolumn{2}{|l|}{ General psychiatric care } \\
\hline Out-patient care & $10 / 10$ \\
\hline In-patient care & $4 / 10$ \\
\hline Both & $4 / 10$ \\
\hline
\end{tabular}

psychiatric care at a general psychiatric clinic in an urban area in southern Sweden. All of the women self-reported affective disorders as a primary reason for seeking general psychiatric care. Two of the women had been abused during childhood, one woman as an adult and seven women were abused both as a child and adult.

\subsection{Data Collection}

The interview started with an open question "Can you tell me how your experiences of physical, emotional or/ and sexual abuse have influenced your mental ill health". The interviewees were encouraged to describe abuse situations that influenced their mental ill health in order to gain a deeper understanding for the phenomena. The interviews were conducted between January and November 2011 and lasted on average 65 minutes, ranging between 35 - 120 minutes. The total interview time was 11.05 hours and the total transcribed material consisted of 160 pages (Times New Roman 12, line spacing 1.5). All the interviews were audio taped and transcribed verbatim by the first author. A pilot study, with two interviews was conduct in January-February 2011 and included in the material.

\subsection{Data Analyses}

Manifest and latent content analysis was used to analyze the interviews, which according to Berg [24] provides a surface structure as well as a deep structural meaning of the transcribed interviews. The first and the last author separately read the transcribed material several times in order to gain a deeper understanding of what was revealed in the text. Our naïve understanding was discussed and shared in order to be able to understand our pre-under standing in an attempt to assure neither exaggeration nor understatements during the faces of interpretation of the data. Meaning units, which described the women's experiences of abuse and mental illness, were selected from the text and condensed by the first author and shared and discussed with the last author. The material was coded separately at first and then compared. The coded material was similar and the differences that occurred referred to the use of different words and sentence length, while the core of the code was identical. The condensed coded meaning units were then repeatedly read by the first and last author who separately established subcategories. The processes of analyzing continued with the comparison and discussions before consensus concerning the subcategories were reached that also included setting the coding frames for each subcategory. The subcategories were then organized in relation to categories and a theme emerged.

Every single meaning unit's placement in relation to subcategories and categories were visualized, which was used to support and validate the interpretation performed in relation to the surface of the data (manifest analysis), as well as the more profound depth in the interpretation of the data (latent analysis). The first, fifth and tenth interviews together with a written description of subcategories, categories and theme to describe the process of analysis were shared with, and read by the other two coauthors. Discussions concerning the subcategories, categories and theme took place in order to reach consensus. The first author has experience from the clinical psychiatric research field and together with the third author experiences as a psychiatric and mental health nurse. The last author has experience as a nurse within emergency and hospital care and advanced home care as well as clinical research within these fields. The second author has no clinical experience as a nurse but experiences from the research fields of victimology and criminology.

\subsection{Ethical Consideration}

The first author talked to the women before the interviews about the possible discomfort that could occur due to the topic of the interview. Questions were asked concerning support in case of discomfort, the women's own strategies and where they would turn for help and support. The first author made sure that every woman had somewhere to get help and support before starting the interview. The women were also informed that the interviewer had worked as a psychiatric and mental health 
nurse and that she had previous experience of talking to women about abuse. They were informed that participation was voluntary, that they had control over the interview, such as the right to end the interview at any time or to refuse to answer further questions. The women had an opportunity to talk and recuperate if needed after each interview. They were informed that their participation would be anonymous, which according to Berg [24] means that they would be nameless. Demographic data would be presented as a group and quotations were chosen so as not to reveal identities. The study was approved by the research ethics review board at Lund University (Dnr: 2010/3).

\section{RESULTS}

The findings are presented within the structure of the category system that emerges from the narratives. The overall theme emerging from the narratives, "Being vulnerable and without protection in a frightful reality that limits one's possibilities of living and being the person one wishes to be" captures the essence shown in the categories. Lives were the experience of violence has left an uncertainty of who you are and who you once were.

The categories; Living in fear that persistently influences the substance of life, Living with the sense of being worthless, Living with a constant question about who you are and Living between hope and despair emerged from the subcategories. These subcategories are underlined and presented in the categories.

\subsection{Being Vulnerable and without Protection in a Frightful Reality that Limits One's Possibilities of Living and Being the Person One Wishes to Be}

All of the women described fear and vulnerability as a limitation preventing them from living their lives to the fullest. The women described their mental ill health, not only in medical terms and as disorders but in terms of shame and guilt, worthlessness and powerlessness. Their life was lived in a dynamic duality of desires to live their lives as well as thoughts of suicide and despair. The women's experiences of abuse had an explicit influence on their daily life and self-images and a longing for another life arose from the narratives:

I had been a different person today without these experiences. It makes me sad. I feel stupid, very stupid, how could this happen to me, how could I stay and why did I not see when everybody said that this was not good (6).

\subsection{Living in Fear that Persistently Influence the Substance of Life}

Living in constant fear was one of the consequences of abuse emerging from the text, where frightful experiences resulted in mental ill health. Their lives contained fear as well as the necessity to escape the abusive environment and thus influenced the very substance of daily existence. Fear of the abuser and not having the ability to prevent or stop the abuse emerged as feelings of guilt. Emotions of constant fear and preparedness controlled lives, and strategies were established in order to control and cope with this constant fear. Avoiding situations and people who reminded of abusers as well as having a readiness to run or defend themselves arose from the stories, where other people's anger was frightful, especially if alcohol was involved:

I'm always prepared that something can happen and I think about it constantly. I always wear low heels so I can run home late at night (1).

One consequence of fear was described as a sense of guilt and shame. The women felt guilty and ashamed being afraid of leaving an abusive spouse or family, for not reporting to the police and towards themselves for causing suffering to people close to them.

In order to survive and due to fear a necessity to escape evolved. Some narratives revealed difficulties in breaking free and a dependence on social support for their escape. Being admitted to rehabilitation clinics were described as and one way out of an abusive relationship. Some fled, and left everything behind, while others chose alcohol, solitude, being an "emotional robot", daydreaming and thoughts of suicide as a way of escaping the abuse:

I'd been deprived of the feeling of being free, I've become introverted fled to alcohol where I could feel free (5).

\subsection{Living with the Sense of Being Worthless}

The interviews revealed that the women felt they had been transformed due to their experiences of abuse, which was expressed in terms of them stating that their lives would have been completely different without these experiences. Such a life would provide a fair chance of having a good life and mental well-being. Feelings of worthlessness, low self-esteem and a sense of being invisible were consequences of the abuse that was revealed in the interviews, as well as feelings of not being believed, protected or comforted. Narratives revealed childhood abuse and a longing for the love of a parent. Being exposed to manipulation, violent acts from spouses, parents, family members and strangers emerged from the text and being inhibited in following one's own will, being controlled by a spouse or parent or being told that they were stupid affected their daily lives:

He made me feel stupid, that I did things the wrong way. I easily forget things when I don't have to concentrate, and then he said that I had said things and so on, 
He didn't say nasty things but I got a feeling of worthlessness. He denies it now but he is very manipulative (9).

Being bullied in school and at work, having few friends and being insecure in social relationships resulted in isolation. Feelings of being different and being jealous of other children during childhood were revealed. Experiences from growing up in foster care led to perceptions of being ignored in the family and being looked at as different and not likeable:

I was bullied in school and it affected my self-esteem. I never had new clothes. I always wore homemade clothes and knitted socks when others wore jeans and T-shirts (6).

Life did not turn out as expected where feelings of meaninglessness lead to anxiety, depression, and thoughts of suicide. A sense of powerlessness, which was due to feelings of being easy targets, and of living in hostile environments, was described as distressing. The narratives contained descriptions of loneliness and feelings of being invisible and childhood experiences of witnessing a mother being abused were more traumatizing then being abused oneself:

I felt invisible and wished that I would be hit by a car, so people would notice me. But it was even worse seeing your mother being abused, then being abused yourself (10).

\subsection{Living with a Constant Question about Who You Are}

Experiencing abuse and growing up in abusive environments had a significant influence on life in terms of selfimage and mental ill health. A hostile environment, where insecurity and feelings of not having any boundaries influenced their life conditions. A constant sense of insecurity about doing right, a sense of not pleasing people as well as difficulties in saying "no" influenced daily life. Keeping personal boundaries towards others was never learned or experienced during childhood, which was described as containing nervousness and feelings of being lost among others. Living with a constant question about oneself generated a lack of initiative and a distrust of feelings. Being afraid of conflicts created strategies such as avoiding situations or people that might be difficult, which thus initiated adjustments and a necessity to build walls against others in order to "stay out of trouble":

I have difficulties with boundaries and I make myself small and evasive. I have a hard time saying No (1).

Harassment towards oneself was revealed as not being loveable, being stupid and incompetent. Self-contempt such as a self-image of being ugly and self-hating arose from the narratives, where the urge to punish oneself through anorectic and bulimic behavior, alcohol and weight gain were revealed as well as thoughts of suicide, suici- dal communication and self-harm:

You feel disgusting because of the abuse and I've cut my arm to pieces. I'm already so ugly and disgusting so it doesn't matter (7).

\subsection{Living between Hope and Despair}

Living between hope and despair describes the movement from hope for the future and a better life to hindrances due to mental illness. One described consequence of the abuse that emerged from the data was the change in personality and oneself.

The narratives described a need to achieve and to keep up appearances. To achieve top grades in school and a perfect home were important as well as to hide the abuse and despair from others. Top grades were described as the only way to be noticed during childhood.

The mental ill health revealed in the interviews could concern a lack of concentration, insomnia, apathy, "in a bubble" fatigue, and feelings of unreality which reduced freedom of action for the women. Other concerns in relation to being abused could be nervousness in social encounters, inhibition, loss of friends and having to balance emotions. A sadness due to not being able to endure motherhood, because of feelings of physical and emotional limitation as well as their own experiences of growing up in a family with mental disorders was visible in the stories:

I go to a psychiatrist and we talk a lot about children. I have had lots thoughts about whether it would be physically possible to have a child. I feel so inhibited (2).

The narratives describe the hopes for the future and the importance and necessity for support from significant others, psychiatric staff and for tools with which to manage daily life were as hope for improvement. A need to feel one's emotions, to manage without antidepressive medication, to understand the reason for the abusive act and a desire for a better life was also experienced. Even so, life was lived in a dynamic duality of desires to live, to raise children, to accept one's destiny as well as thoughts of suicide and despair concerning hope for the future:

I can and I have the possibility to be well. Learn how to function. But when it's bad, it's hopeless. Doesn't matter, how hard I try, I'll always be different (3).

\section{DISCUSSION}

The present study contributes to the body of knowledge of women's experience of abuse and impact on their mental ill health as described in their own words. All of the women in the study were patients at a general psychiatric clinic, attending in- and/or outpatients' psychiatric care. The women were being treated for mental health problems, which makes it difficult for clinicians and nurses 
to discern which symptoms are due to their mental health status and which are symptoms of abuse. However, the study presents how the women described how their experiences of abuse influenced their mental ill health. Our intention was not to have a predetermined definition of mental ill health or a focus on their diagnosis, because such a definition could limit and influence the women's own descriptions of their mental ill health and thus affect the results.

The interviewees in the present study expressed that the abuse had changed them as individuals thus enhancing the impact violence had on these women's lives and their mental ill health. All of the women had experienced abuse on some occasions during their life time and a majority of them since childhood. Research has shown that growing up in a violent and abusive environment has appeared to have an impact on mental health as an adult [13,25-28]. Depression and anxiety were the most common health consequences among children and young people between 15 - 21 years who have been exposed to physical or sexual abuse [29]. Witnessing parental abuse, poverty and exposure to abuse whilst growing up is, according to Howard et al. [13], a risk factor for exposure to domestic violence as an adult.

One experience spoken of the women in our study was the balance between hope and despair. They hoped for recovery and change but had also feelings of limitations due to nervousness and mental ill health. The results of our study reveal that women in a general psychiatric context experience similar symptoms of abuse as abused women in other contexts. Our concern, however, is that there might be a risk that the abuse is misinterpreted or that a focus on the mental illness will divert the focus of nursing care and support if the abuse is not recognized.

In Bengtsson-Tops and Tops [30] a study of abused women seeking psychiatric care showed an impact on a daily life such as social problems and interpersonal problems. Symptoms of depression and physical self-destructive behavior were also described by the abused women. Almost all of the women in the present study also experienced the same consequences together with feelings of guilt and shame, and fear. In a Swedish study by Lundgren et al. [31] half of the women stated that experiencing violence had had a negative effect on them and their lives. Suicidal ideation was, for many of the women in the present study, a symptom and consequence of abuse as well as a way of escaping the violence. Similar results are seen in other research concerning violence against women [31-33].

Studies concerning violence against women are important due to the tremendous impact violence has on women's lives. Nurses in health care settings have, however, expressed difficulties in identifying violence against women [23].
The results of our study indicate symptoms that could easily be hidden within a psychiatric diagnosis or as general mental ill health. Experiences of childhood abuse and violent acts towards the women during adulthood emerged during the interviews as well as images of violent and hostile environments. Abuse from perpetrators living close to them, such as parents, step parents, relatives, acquaintances and spouses were the most common, but violence from strangers was also experienced. It is difficult to assess which emotions and feelings are due the mental ill health, but on the other hand these symptoms are described by the women as being symptoms of abuse. In order to be able to care and support in an optimal way it is evident that nurses working in a general psychiatric context need to ask all women, demonstrating with symptoms and emotions as described in the results of the present study, about experiences of abuse.

A sample of ten is small and could be seen as a limitation although every story is unique and individual. Other limitations are the difficulty to reach the severe victimized women and thereby capture the experiences of all aspects of abuse and the consequences. The severity of mental ill health among the sample could be a factor that prevented further women from participating. Nevertheless, for insurance of rigour in the findings we aimed for trustworthiness in accordance with standard criteria for qualitative research [34].

\section{CONCLUSION}

The results show that abused women in a general psychiatric context describe their mental ill health not only in terms of depression, anxiety, suicidal ideation and selfharm, but also as feelings of hope and despair, fear, worthlessness and living with a constant question about whom they are. The abuse reduces freedom of action, leads to feelings of insecurity and of not having any boundaries, of isolation, of self-contempt and leads to a need to escape. This study provides knowledge of abused women self-reported mental ill health in relation to abuse. A better understanding of how abused women describe their mental ill health contributes to a deeper understanding of the lives and mental ill health of abused women. It is relevant that all women seeking general psychiatric care are asked if they have experienced abuse sometimes during their lifetime and about the symptoms and the consequences of the abuse may have had on their mental ill health and daily lives.

\section{DECLERATION OF INTEREST}

The authors report no conflicts of interest. The authors alone are responsible for the content and writing of the paper. Grants from the Fund for Victims of Crime funded this study. 


\section{ACKNOWLEDGEMENTS}

The authors wish to gratefully thank the participating women who generously shared their experiences and life stories with us. We also want to thank Professor David Brunt for revising our English.

\section{REFERENCES}

[1] Watts, C. and Zimmerman, C. (2002) Violence against women: Global scope and magnitude. The Lancet, 359, 1232-1237.

http://dx.doi.org/10.1016/S0140-6736(02)08221-1

[2] Heise, L., Ellsberg, M. and Gottemoeller, M. (1999) Ending violence against women. Johns Hopkins University School of Public Health, Center for Communications Programs, Baltimore.

[3] Tjaden, P. and Thoennes, N. (2000) Full report of the prevalence, incidence, and consequences of violence against women. Findings from the national violence against women survey, Department of Justice.

[4] Krug, E.G., Mercy, J.A., Dahlberg, L.L. and Zwi, A.B. (2002) The world report on violence and health. The Lancet, 360, 1083-1088. http://dx.doi.org/10.1016/S0140-6736(02)11133-0

[5] Ellsberg, M., Jansen, H.A.F.M., Heise, L., Watts, C.H. and Garcia-Moreno, C. (2008) Intimate partner violence and women's physical and mental health in the WHO multi-country study on women's health and domestic violence: An observational study. The Lancet, 371, 11651172. http://dx.doi.org/10.1016/S0140-6736(08)60522-X

[6] World Health Organization (2010) Child maltreatment, Fact sheet $\mathrm{N}^{\circ} 150$.

http://www.who.int/mediacentre/factsheets/fs150/en/inde x.html

[7] Afifi, T.O. (2012) The relationship between child maltreatment and Axis I mental disorders: A summary of the published literature from 2006 to 2010. Open Journal of Psychiatry, 2, 21-32. http://www.SciRP.org/journal/ojpsych/

[8] Ellsberg, M. and Heise, L. (2005) Researching Violence against women: A practical guide for researchers and activist. World Health Organization, Washington DC.

[9] Friedman, S.H. and Loue, S. (2007) Incidence and prevalence of intimate partner violence by and against women with severe mental illness. Journal of Women's Health/ The Official Publication of the Society for the Advancement of Women's Health, 16, 471-480.

[10] Kelmendi, K. (2013) Violence against Women: Methodological and Ethical Issues. Psychology, 4, 559-565. http://dx.doi.org/10.4236/psych.2013.47080

[11] Campbell, J.C. (2002) Health consequences of intimate partner violence. The Lancet, 359, 1331-1336. http://dx.doi.org/10.1016/S0140-6736(02)08336-8

[12] Coker, A. (2006) Preventing intimate partner violence, how we will rise to this challenge. American Journal of Preventive Medicine, 30, 528-529. http://dx.doi.org/10.1016/j.amepre.2006.03.002

[13] Howard, L.M., Trevillion, K. and Agnew-Davies, R.
(2010) Domestic violence and mental health. International Review of Psychiatry, 22, 525-534.

[14] Choudhary, E., Smith, M. and Bossarte, R.M. (2012) Depression, anxiety, and symptom profiles among female and male victims of sexual violence. American Journal of Men's Health, 6, 28-36. http://dx.doi.org/10.1177/1557988311414045

[15] Dillon, G., Hussain, R., Loxton, D. and Rahman, S. (2013) Mental and physical health and intimate partner violence against women: A review of the literature. International Journal of Family Medicine, 2013, 313909. http://www.hindawi.com/journals/ijfm/2013/313909/abs/

[16] Stefansson, C. (2006) Chapter 5.5: Major public health problems-Mental ill-health. Scandinavian Journal of Public Health, 34, 87-103. http://dx.doi.org/10.1080/14034950600677105

[17] Howard, L.M., Trevillion, K., Khalifeh, H., Woodall, A., Agnew-Davies, R. and Feder, G. (2010) Domestic violence and severe psychiatric disorders: Prevalence and interventions. Psychological Medicine, 40, 881-893. http://dx.doi.org/10.1017/S0033291709991589

[18] Alhabib, S., Nur, U. and Jones, R. (2010) Domestic violence against Women: Systematic review of prevalence studies. Journal of Family Violence, 25, 369-382.

http://dx.doi.org/10.1007/s10896-009-9298-4

[19] Bengtsson-Tops, A., Markstrom, U. and Lewin, B. (2005) The prevalence of abuse in Swedish female psychiatric users, the perpetrators and places where abuse occurred. Nordic Journal of Psychiatry, 59,504-510. http://dx.doi.org/10.1080/08039480500360732

[20] Oram, S., Trevillion, K., Feder, G. and Howard, L.M. (2013) Prevalence of experiences of domestic violence among psychiatric patients: A systematic review. British Journal of Psychiatry, 202, 94-99. http://dx.doi.org/10.1192/bjp.bp.112.109934

[21] The Swedish Society of Nursing and the Swedish Association of Psychiatric and Mental Health Nurses (2012) Competence description for registered nurses specializing in psychiatric care.

[22] Carretta, C.M. (2008) Domestic Violence, A worldwide exploration. Journal of Psychosocial Nursing and Mental health services, 46, 26-35. http://dx.doi.org/10.3928/02793695-20080301-02

[23] Sundborg, E.M., Saleh-Stattin, N., Wändell, P. and Törnkvist, L. (2012) Nurses' preparedness to care for women exposed to intimate partner violence: A quantitative study in primary health care. BioMed Central Nursing, 10, 1. http://www.biomedcentral.com/1472-6955/11/1/

[24] Berg, B. (2008) Qualitative research for the social sciences. Pearson Education, Upper Saddle River.

[25] Nilsson, G., Bengtsson-Tops, A.B. and Persson, L. (2005) Childhood abuse in Swedish female users of psychiatric services. Journal of Psychiatric and Mental Health Nursing, 12, 365-371.

http://dx.doi.org/10.1111/j.1365-2850.2005.00848.x 
[26] Sunnqvist, C., Westrin, A. and Traskman-Bendz, L. (2008) Suicide attempters: Biological stressmarkers and adverse life events. European Archives of Psychiatry and Clinical Neuroscience, 258, 456-462. http://dx.doi.org/10.1007/s00406-008-0819-6

[27] Becker, K.D., Stuewig, J. and McCloskey, L.A. (2010) Traumatic stress symptoms of women exposed to different forms of childhood victimization and intimate partner violence. Journal of Interpersonal Violence, 25, 16991715. http://dx.doi.org/10.1177/0886260509354578

[28] Chou, K.L. (2012) Childhood sexual abuse and psychiatric disorders in middle-aged and older adults: Evidence from the 2007 adult psychiatric morbidity survey. The Journal of Clinical Psychiatry, 73, 1365-1371. http://dx.doi.org/10.4088/JCP.12m07946

[29] Cerdá, M., DiGangi, J., Galea, S. and Koenen, K. (2012) Epidemiologic research on interpersonal violence and common psychiatric disorders: Where do we go from here? Depression and Anxiety, 29, 359-385. http://dx.doi.org/10.1002/da.21947

[30] Bengtsson-Tops, A. andTops, D. (2007) Self-reported consequences and needs for support associated with abuse in female users of psychiatric care. International Journal of Mental Health Nursing, 16, 35-43. http://dx.doi.org/10.1111/j.1447-0349.2006.00442.x

[31] Lundgren, E., Heimer, G., Westerstrand, J. and Kalliokoski, A.M. (2001) Slagen Dam-Mäns våld mot kvinnor i jämställda Sverige-En omfångsundersökning. Fritzes Offentligapublikationer, Stockholm.

[32] Scheffer-Lindgren, M. and Renck, B. (2008) It is still so deep-seated, the fear': Psychological stress reactions as consequences of intimate partner violence. Journal of Psychiatric and Mental Health Nursing, 15, 219-228. http://dx.doi.org/10.1111/j.1365-2850.2007.01215.x

[33] Devries, K., Watts, C., Yoshihama, M., Kiss, L., Schraiber, L.B., Deyessa, N., Heise, L., Durand, J., Mbwambo, J., Jansen, H., Berhane, Y., Ellsberg, M. and GarciaMoreno, C. (2011) Violence against women is strongly associated with suicide attempts: Evidence from the WHO multi-country study on women's health and domestic violence against women. Social Science \& Medicine, 73, 79-86.

http://dx.doi.org/10.1016/j.socscimed.2011.05.006

[34] Graneheim, U.H. and Lundman, B. (2004) Qualitative content analysis in nursing research: Concepts, procedures and measures to achieve trustworthiness. Nurse Education Today, 24, 105-112. http://dx.doi.org/10.1016/j.nedt.2003.10.001 